North American Journal of Aquaculture 61:74-78, 1999

(C) Copyright by the American Fisheries Society 1999

\title{
Evaluation of Two Sizes of Hybrid Striped Bass for Introduction into Small Ponds
}

\author{
J. WeSLEY NEAL* \\ Fisheries and Wildlife Sciences, North Carolina State University, \\ Campus Box 7646, Raleigh, North Carolina 27695, USA \\ JAMES A. Rice \\ Department of Zoology, North Carolina State University, \\ Campus Box 7617, Raleigh, North Carolina 27695, USA \\ RichaRd L. Noble \\ Fisheries and Wildlife Sciences, North Carolina State University, \\ Campus Box 7646, Raleigh, North Carolina 27695, USA
}

\begin{abstract}
Private recreational fisheries in small impoundments provide a potential new market for the growing industry producing hybrid striped bass Morone saxatilis. We estimated growth, condition, and survival of hybrid striped bass (female striped bass $\times$ male white bass $M$. chrysops) in two small ponds with established fisheries for largemouth bass Micropterus salmoides and bluegill Lepomis macrochirus that eventually experienced severe weather-induced fish kills $266 \mathrm{~d}$ and 348 $\mathrm{d}$ after stocking. Both ponds were stocked with 40 phase 2 (120-169 mm total length, TL) and 22 phase 3 (241$344 \mathrm{~mm}$ TL) hybrid striped bass/ha. Growth and condition were monitored from introduction until the occurrence of fish kills. Fish collections immediately following the kills allowed minimum estimates of survival for time at large before each event. Mean growth rates were near $0.35 \mathrm{~mm} / \mathrm{d}$ for phase 2 hybrids and ranged from 0.13 to $0.21 \mathrm{~mm} / \mathrm{d}$ for phase 3 hybrids. Mean relative weight $\left(W_{r}\right)$, which at the time of stocking was optimal (100), decreased to near 85 for phase 2 hybrids and near 75 for phase 3 hybrids after $300 \mathrm{~d}$ at large. Adjusted annual survival estimates over the period from stocking until initiation of the fish kills were $42.3 \%$ and $58.6 \%$ for phase 2 hybrid striped bass and $56.0 \%$ and $66.6 \%$ for phase 3 fish. Based on purchase price and relative survival of the two size-groups, phase 2 hybrid bass are the more economical choice for stocking recreational ponds that have established sport fish communities.
\end{abstract}

Aquaculture of the hybrid produced from female striped bass Morone saxatilis and male white bass $M$. chrysops (hereafter referred to as hybrid bass) is a growing industry in the United States (Rhodes and Sheehan 1991; Smith and Jenkins 1996). Estimated production of food-size fish reached 5,180 metric tons in 1995, which was more than double

* Corresponding author: jwneal@unity.ncsu.edu Received February 9, 1998 Accepted July 24, 1998 the landings of commercial striped bass fisheries of the Atlantic coast. In the past 20 years, many research and development programs have examined the efficiency of different aquaculture systems for culturing striped bass and its hybrids (see review by Carlberg et al. 1984; Smith et al. 1985; Kelly and Kohler 1996). These studies have focused mainly on intensive culture for the food fish market, and little attention has been given to the potential for nonintensive stocking of hybrid bass in ponds for recreational purposes.

Successful introductions of hybrid bass into large reservoirs have resulted in quality fisheries supporting more than $15 \%$ of all freshwater angling days (USFWS 1993). This success has created an interest in using these fish to enhance and diversify fisheries in small impoundments. Until recently, hybrid bass were not readily available for stocking in private waters, but the establishment of the aquaculture industry has created the potential to add hybrid bass to traditional warmwater pond fisheries. Development of effective stocking and management guidelines for hybrids in small ponds could also open a substantial new market for the aquaculture industry because periodic restocking would be required.

Until recently, attempts to create recreational pond fisheries with hybrids have failed due to low survival of fry (Layzer and Clady 1984). Few attempts at stocking advanced fish have occurred because of the previous high cost of obtaining them for private use. Because larger hybrid individuals show increased survival, it may be advantageous to stock at a larger size (Layzer and Clady 1984; Curry and Wilson 1987; Moore et al. 1991). With advances in hybrid production, private citizens and organizations can purchase larger hybrids economically for stocking in recreational fisheries. 
TABLE 1.-Mean measurements of physicochemical characteristics recorded monthly in ponds 1 and 2. Parenthetical values are the minimum and maximum of each feature.

\begin{tabular}{lcc}
\hline \multicolumn{1}{c}{ Characteristic } & Pond 1 & Pond 2 \\
\hline Transparency $(\mathrm{cm})$ & 42 & 58 \\
& $(27-59)$ & $(24-128)$ \\
$\mathrm{pH}$ & 8.3 & 8.7 \\
& $(7.4-10)$ & $(7.3-11)$ \\
Alkalinity $(\mathrm{mg} / \mathrm{L})$ & 36 & 40 \\
& $(34-37)$ & $(32-55)$ \\
Surface temperature $\left({ }^{\circ} \mathrm{C}\right)$ & 19.2 & 19.5 \\
& $(5.5-36)$ & $(5-35)$ \\
\hline
\end{tabular}

In the course of a study to compare growth and condition of two sizes of hybrid bass in North Carolina ponds containing established populations of largemouth bass Micropterus salmoides and bluegill Lepomis machrochirus, we encountered large-scale weather-related fish kills in two ponds. Because both events resulted in the death of most fish larger than $150 \mathrm{~mm}$ (indicated by postkill gillnetting), we were able to perform a nearly complete census of hybrid bass during clean-up efforts in the days immediately following each fish kill. From these fish, we also were able to obtain minimum estimates of survival from stocking until the fish kills.

The two ponds evaluated were not open to fishing harvest. Pond 1 was 3.6 ha and contained a balanced largemouth bass-bluegill community; pond 2 was 2.4 ha and was characterized by largemouth bass overcrowding and limited bluegill recruitment (Neal 1996). The physicochemical characteristics were typical of many small southeastern ponds (Table 1). The ponds were stocked with two size-groups of hybrid bass on 16 September 1994. The group of smaller fish (phase 2) ranged in total length (TL) from 120 to $169 \mathrm{~mm}$, with a mean TL of $142 \mathrm{~mm}$. The group of larger fish (phase 3) ranged from 241 to $344 \mathrm{~mm}$. Due to the extensive range of phase 3 lengths, this group was divided into 25 -mm length-groups, each receiving a groupspecific mark, to help refine estimates of change in total length over time. Stocking rates were the same for both ponds to produce densities of 40 phase 2 fish/ha and 22 phase 3 fish/ha. Hybrid bass were at large for $266 \mathrm{~d}$ in pond 1 and $348 \mathrm{~d}$ in pond 2 before fish kills occurred.

Hybrid bass were periodically collected for analysis of growth and condition with hook and line, electrofishing, and short-term gill netting. Total length $(\mathrm{mm})$, weight $(\mathrm{g})$, and mark (phase 3 only) of each fish were recorded, stomach contents were removed with plastic esophageal tubes (Van Den Avyle and Roussel 1980), and the fish were immediately returned to the water. Hybrid bass were also collected following the occurrence of each fish kill, at which time all hybrid bass found floating along the shoreline were recovered and total lengths were recorded. Average daily growth rate $(\mathrm{mm} / \mathrm{d})$ for each fish was calculated from the difference between the total length at capture and the mean length at stocking. Growth in length was used instead of growth in weight because most data were collected from fish that had been dead for 2 d. Fish weight typically tends to increase in freshwater after death due to cessation of osmoregulation (Grinstead et al. 1978; Lyons et al. 1991). Growth rates of size-groups were compared using an independent $t$-test on mean growth rates. Relative weight ( $W_{r}=$ ratio of a fish's weight to the weight of a "standard" fish of the same length) of fish collected at times other than the fish kills was used to estimate condition of individual fish. Relative weight was calculated using the standard weight equation of Brown and Murphy (1991). Linear regression on relative weight versus time at large facilitated interpretation of changes in condition.

The fish kills presented an unexpected opportunity to estimate survival for the period from stocking to the time of the fish kill in each pond. These kills were the result of unusual circumstances that also caused the death of largemouth bass and bluegills, typically successful pond species. Both kills resulted from extreme anoxic conditions during early morning rainstorms; each pond destratified allowing deeper water with high oxygen demand to mix with the low oxygen surface water. These ponds did not have a history of fish kills, so we considered these events to be unusual.

The minimum survival estimates were a ratio of the number of hybrid bass collected following the fish kill to the number originally stocked. These estimates were conservative because some hybrid bass may have survived or were not recovered. A Petersen mark-recapture population estimate was in progress for largemouth bass $(>250 \mathrm{~mm})$ in pond 1 when the kill occurred. Of 200 marked largemouth bass, 122 (61\%) were recovered during clean up. This ratio was used for adjustment of minimum survival estimates for hybrid bass to account for fish not recovered by multiplying survival estimates by the marked largemouth bass recovery rate (1/0.61 or 1.64$)$. This adjustment assumed equal susceptibility of largemouth and hybrid bass during each fish kill, no size-specificity 


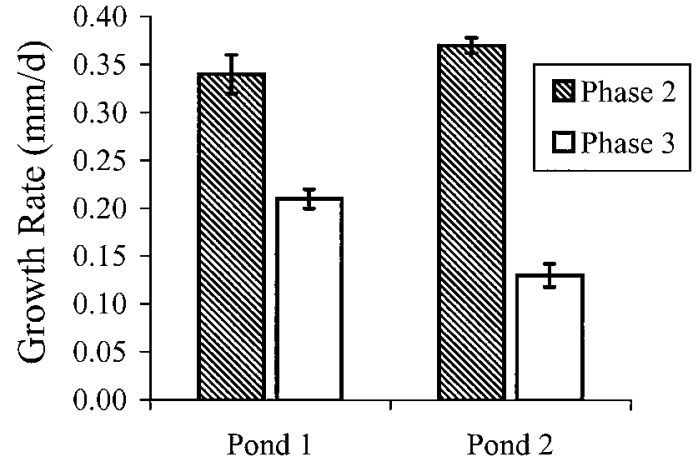

FIGURE 1.-Mean daily growth rates of hybrid striped bass in ponds 1 and 2 . Growth rates were calculated over the time at large for each fish. Range and mean time at large for hybrid striped bass from each pond were as follows: pond $1,125-165 \mathrm{~d}$, mean $=161.8 \mathrm{~d}$; pond 2 , $269-320 \mathrm{~d}$, mean $=277.2 \mathrm{~d}$.

within the marked range, similar postmortem movement (e.g., float to shore), and similar recovery rates in pond 2 .

Phase 2 hybrids exhibited faster growth in total length than phase 3 fish $(t=4.5$, df $=2, P<$ $0.05)$, and growth rates were variable among ponds
(Figure 1). Phase 2 fish daily growth was 0.34 and $0.37 \mathrm{~mm} / \mathrm{d}$ (93 and $133 \mathrm{~mm} /$ year) in ponds 1 and 2 , respectively, and phase 3 growth rates were 0.21 and $0.13 \mathrm{~mm} / \mathrm{d}$ ( 78 and $48 \mathrm{~mm} /$ year, respectively). These growth rates are based on the total time at large for each individual before capture and represent an average growth rate that included seasonal periods of both slow and rapid growth. Variation in estimated growth rates between ponds may be explained by differences in the times at large because pond 2 hybrid bass were exposed to excessive summer temperatures that may have limited growth. However, it is more likely that phase 3 hybrid bass in this pond competed for prey resources with largemouth bass, which were numerous and stunted at a similar size as the phase 3 hybrids.

Hybrid bass relative weight decreased rapidly upon introduction for both size-classes in both ponds (Figure 2). Phase 2 hybrids had a much higher $W_{r}$ than phase 3 fish at introduction (117 versus 88), but their condition declined to approximately 85 after $300 \mathrm{~d}$ at large. Phase 3 hybrid bass showed a similar decrease in $W_{r}$, averaging 75 after 300 d. Even though hybrids began to grow

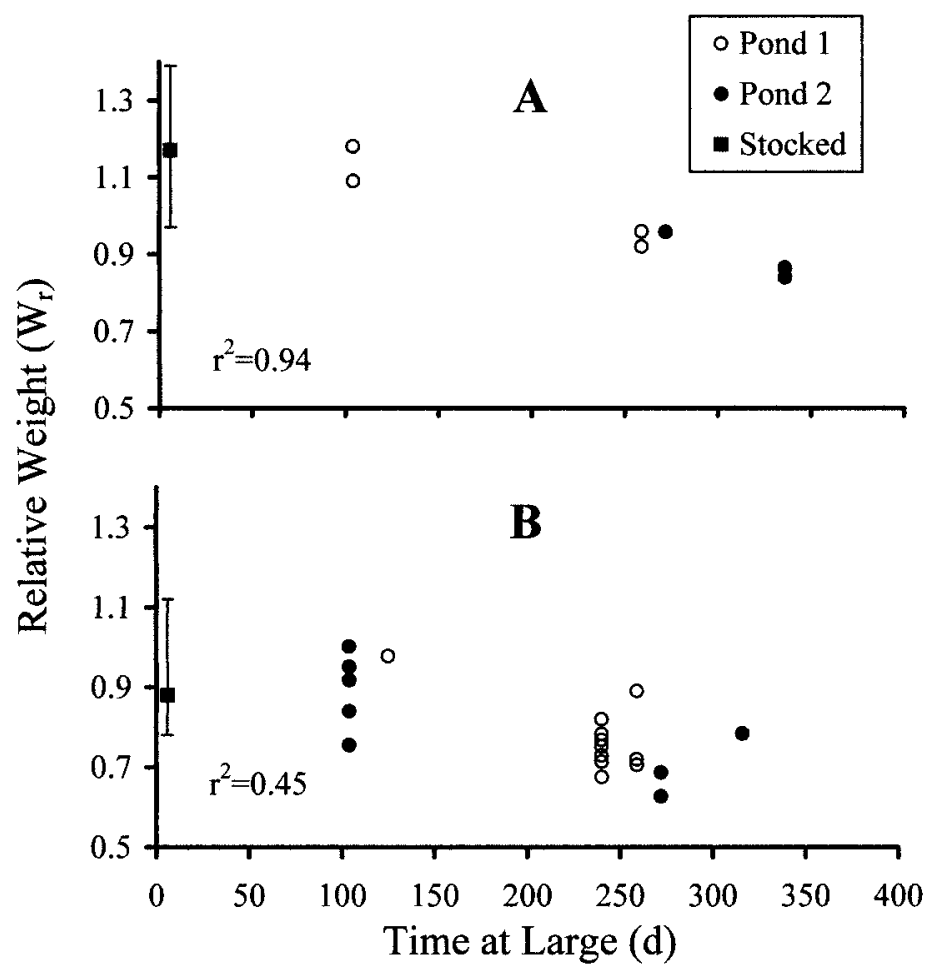

FIGURE 2.-Relative weight ( $W_{r}$ ) of (A) individual phase-2 and (B) individual phase-3 hybrid striped bass collected before the occurrence of fish kills. Mean $W_{r}$ at stocking is given with range indicated by error bars. 
in total length the next spring following introduction, $W_{r}$ continued to decrease. Similar changes in condition have been seen in larger ponds (Neal 1996), where $W_{r}$ for phase 2 and phase 3 hybrid bass decreased rapidly before stabilizing around 70 .

Observed growth rates were not as high as many rates reported for hybrid bass in larger impoundments (Ott and Malvestuto 1984; Borkowski and Snyder 1985). Hybrids were stocked in mid-September, however, and most likely experienced a period of slow growth during the winter months. Diet samples showed that hybrids relied solely on insect larvae (dipterans) during winter and then switched to fish prey when larval centrarchids became available in spring. Similar diets in farm ponds have been reported (Neal 1996), which suggests that hybrids should be stocked in the spring (April-May) when larval fish prey are becoming available. An early spring stocking could increase survival by allowing the hybrids to exploit the larval centrarchid prey base, thus increasing body size before the first overwintering period.

Although growth rates in this study were not as high as in some reservoirs, they were high enough to produce minimum harvest-size fish $(>305 \mathrm{~mm})$ from phase 2 stocking in as little as 1.2 years (based on pond 2 growth rates). Spring stocking should achieve harvestable-size fish in less time by eliminating the initial slow-growth period experienced with fall stocking. Supplemental feeding with commercial diets, which is popular in many private fishing operations, would further accelerate hybrid growth and enhance condition, but could be cost-prohibitive for some recreational fisheries.

During clean-up efforts following each fish kill, a higher proportion of phase 3 hybrids were collected than phase 2 fish. This translated into higher minimum survival estimates for phase 3 hybrid bass than for phase 2 hybrids (which was expected) because phase 3 fish were larger and should have been less vulnerable to predators, such as largemouth bass. Recovery was $35.4 \%$ and $37.5 \%$ for phase 2 hybrid bass in ponds 1 and 2, respectively, whereas $42.6 \%$ and $46.9 \%$ of the phase 3 hybrids originally stocked were recovered. Adjusted survival rates using the largemouth bass recovery rate were 1.64 times higher (Table 2). When the adjusted survival was projected to a 1-year period, adjusted annual survival estimates were $42.4 \%$ and $58.6 \%$ for phase 2 hybrid bass and $56.0 \%$ and $66.6 \%$ for phase 3 hybrid bass.

Minimum survival estimates of hybrid bass in this study were comparable to survival estimates
TABLE 2.- Survival estimates for hybrid bass (female striped bass $\times$ male white bass) in pond 1 after $266 \mathrm{~d}$ at large and in pond 2 after $348 \mathrm{~d}$ at large. Estimates are based on the number of hybrid striped bass collected following fish kills and have been adjusted (multiplied by $1.64)$ by the largemouth bass recovery rate and extrapolated to 1 year.

\begin{tabular}{ccccccc}
\hline & & & & \multicolumn{2}{c}{ Adjusted } \\
\cline { 5 - 6 } $\begin{array}{c}\text { Pond and } \\
\text { size-class }\end{array}$ & Number & $\begin{array}{c}\text { Number } \\
\text { stocked }\end{array}$ & $\begin{array}{c}\text { Minimum } \\
\text { collected }\end{array}$ & $\begin{array}{c}\text { At large } \\
(\%)\end{array}$ & $\begin{array}{c}\text { Annual } \\
\text { survival } \\
(\%)\end{array}$ & $\begin{array}{c}\text { survival } \\
(\%)\end{array}$ \\
\hline $\begin{array}{c}\text { Pond 1 } \\
\text { Phase 2 }\end{array}$ & 144 & 51 & 35.4 & 58.1 & 42.3 \\
Phase 3 & 81 & 38 & 46.9 & 76.9 & 56.0 \\
Pond 2 & & & & & & \\
Phase 2 & 96 & 36 & 37.5 & 61.5 & 58.6 \\
Phase 3 & 54 & 23 & 42.6 & 69.9 & 66.6 \\
\hline
\end{tabular}

a Phase 2 hybrid bass ranged from 120 to $169 \mathrm{~mm}$ total length (TL) and phase 3 fish ranged from 241 to $344 \mathrm{~mm}$ TL.

from most reservoir studies, and adjusted survival estimates were higher. For example, survival of hybrid bass in Alabama from age 1 to age 2 was 30.9\% (Moss and Lawson 1985). These fish were similar in size to our phase 2 fish, which exhibited a minimum of $37.5 \%$ (58.5\% adjusted) survival after $348 \mathrm{~d}$ in pond 2. After the first year, survival of fish stocked at phase 2 should increase due to larger size and adaptation to the pond environment. Estimated mean total lengths of phase 2 hybrids after 1 year in the ponds were 235 and $275 \mathrm{~mm}$ (based on daily growth rate). This approximates the size of the smaller phase 3 hybrids at stocking and suggests second year survival rates would be similar to those observed for phase 3 fish.

Although survival of phase 3 hybrid bass was higher than that of phase 2 fish, stocking of phase 2 fish should be more economical. The cost of individual phase 3 fish is more than 10 times that of individual phase 2 hybrid bass due to the higher cost by weight $(\$ 4.40 / \mathrm{kg}$ of phase 2 fish versus $\$ 6.60 / \mathrm{kg}$ of phase $3 \mathrm{fish}$ at the time of the study) and the difference in number of fish per unit weight. In addition, phase 2 hybrids grew in 1 year to the size at introduction of the phase 3 group. Thus, if 10 phase 2 hybrid bass are stocked, and 4 fish survive to the end of 1 year (estimated $42.3 \%$ survival in pond 1), there would be 4 phase 3 size fish for the initial price of 1 purchased phase 3 hybrid bass. Unless an immediate fishery is desired, it would be more economically advantageous to stock higher numbers of smaller fish than to stock the larger, more expensive fish.

In conclusion, until the catastrophic fish kill events, hybrid bass survived well in these typical 
small southeastern ponds with established centrarchid communities. Hybrid bass growth was slower in these unmanaged ponds than in large reservoirs or intensive culture, and the decline in condition after stocking indicated that the centrarchid prey base was not ideal for hybrid bass. This suggests that use of hybrid bass in this manner for creation of private fisheries will be limited to low-density stocking for diversification purposes only. However, better results might be obtained in ponds with a different trophic structure that includes soft-rayed fishes, such as clupeids. Supplemental feeding would increase growth rates and condition as well, and could be a viable option in smaller systems and in commercial fee fishing operations.

\section{References}

Borkowski, W. K., and L. E. Snyder. 1985. Evaluation of white bass $X$ striped bass hybrids in a hypereutrophic Florida lake. Proceedings of the Annual Conference Southeastern Association of Fish and Wildlife Agencies 36(1982):83-94.

Brown, M. L., and B. R. Murphy. 1991. Standard weights $\left(W_{s}\right)$ for striped bass, white bass, and hybrid striped bass. North American Journal of Fisheries Management 11:451-467.

Carlberg, J. M., J. C. Van Olst, M. J. Massingill, and T. A. Hovanee. 1984. Intensive culture of striped bass: a review of recent technological developments. Pages 89-127 in J. P. McCraren, editor. The aquaculture of striped bass - a proceedings. University of Maryland, Sea Grant Publication UM-SG-MAP84-01, College Park.

Curry, R. L., and J. L. Wilson. 1987. Survival, growth, and food habits of striped bass in small impoundments. Proceedings of the Annual Conference Southeastern Association of Fish and Wildlife Agencies 39(1985):194-199.

Grinstead, B. G., R. M. Gennings, G. R. Hooper, C. A. Schultz, and D. A. Whorton. 1978. Estimation of standing crop of fishes in the predator-stockingevaluation reservoirs. Proceedings of the Annual Conference Southeastern Association of Fish and Wildlife Agencies 30(1976):120-130.

Kelly, A. M., and C. C. Kohler. 1996. Sunshine bass performance in ponds, cages, and indoor tanks. Progressive Fish-Culturist 58:55-58.

Layzer, J. B., and M. D. Clady. 1984. Evaluation of the striped bass $\times$ white bass hybrid for controlling stunted bluegills. Proceedings of the Annual Conference Southeastern Association of Fish and Wildlife Agencies 35(1981):297-310.

Lyons, B. W., D. L. Cambell, and W. D. Harvey. 1991. Post-mortem weight gain in largemouth bass. Proceedings of the Annual Conference Southeastern Association of Fish and Wildlife Agencies 44(1990):20-26.

Moore, C. M., R. J. Neves, and J. J. Ney. 1991. Survival and abundance of stocked striped bass in Smith Mountain Lake, Virginia. North American Journal of Fisheries Management 11:393-399.

Moss, J. L., and C. S. Lawson. 1985. Evaluation of striped bass and hybrid striped bass stockings in eight Alabama fishing lakes. Proceedings of the Annual Conference Southeastern Association of Fish and Wildlife Agencies 36(1982):33-41.

Neal, J. W. 1996. Hybrid striped bass population characteristics and community impacts in farm ponds: understanding a supplemental predator in established systems. Master's thesis. North Carolina State University, Raleigh.

Ott, R. A., and S. P. Malvestuto. 1984. The striped bass $\times$ white bass hybrid in West Point Reservoir. Proceedings of the Annual Conference Southeastern Association of Fish and Wildlife Agencies 35(1981):641-646.

Rhodes, R. J., and B. Sheehan. 1991. Estimated annual production of commercial hybrid bass growers in the U.S. Striped Bass Growers Association, Technical Report 1, Raleigh, North Carolina.

Smith, T. I. J., and W. E. Jenkins. 1996. Regional development of hybrid striped bass aquaculture in the southeastern United States. Pages 175-179 in T. G. Heggbergett, editor. The role of aquaculture in world fisheries. Proceedings of the World Fisheries Congress, Theme 6. Oxford and IBH Publishing, New Delhi.

Smith, T. I. J., W. E. Jenkins, and J. F. Snevel. 1985. Production characteristics of striped bass (Morone saxatilis) and $\mathrm{F}_{1}, \mathrm{~F}_{2}$ hybrids (M. saxatilis and $M$. chrysops) reared in intensive tank systems. Journal of the World Mariculture Society 16:57-70.

USFWS (U.S. Fish and Wildlife Service). 1993. 1991 national survey of fishing, hunting, and wildlifeassociated recreation. USFWS and U.S. Bureau of the Census, Washington, D.C.

Van Den Avyle, M. J., and J. E. Roussel. 1980. Evaluation of a simple method of removing food items from live black bass. Progressive Fish-Culturist 42: 222-223. 